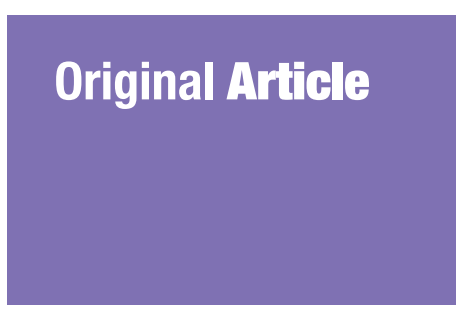

Submitted: 18 Feb 2016 Accepted: 10 Nov 2016 Online: 24 Feb 2017

\section{Perceived Stress and Coping Styles among Malay Caregivers of Children with Learning Disabilities in Kelantan}

\author{
Siti Nor Ismalina IsA ${ }^{1,2}$, Ismarulyusda IsHaK ${ }^{1}$, Azriani $A_{B}$ \\ RaHman $^{3}$, Nur Zakiah Mohd SAAT ${ }^{1}$, Normah Che Din ${ }^{1}$, Syarif \\ Husin LuBIs ${ }^{1}$, Muhammad Faiz MoHD IsMAIL ${ }^{1}$
}

$1 \quad$ Faculty of Health Sciences, Universiti Kebangsaan Malaysia, Jalan Raja Muda Abdul Aziz, 50300 Kuala Lumpur, Malaysia

2 Faculty of Health Sciences, Universiti Teknologi MARA, 4230o Puncak Alam, Selangor, Malaysia

3 Department of Community Medicine, School of Medical Sciences, Universiti Sains Malaysia, Health Campus, 16150 Kubang Kerian, Kelantan, Malaysia

To cite this article: Isa SNI, Ishak I, Ab Rahman A, Mohd Saat NZ, Che Din N, Lubis SH, et al. Perceived stress and coping styles among Malay caregivers of children with learning disabilities in Kelantan. Malays J Med Sci. 2017;24(1):81-93. https://doi.org/10.21315/mjms2017.24.1.9

To link to this article: https://doi.org/10.21315/mjms2017.24.1.9

\begin{abstract}
Background: Caregivers of children with learning disabilities have been shown to experience increased stress and greater negative caregiving consequences than those with typically developing children. There remains a lack of studies focusing on stress and coping mechanisms among caregivers of a wider age group and diagnosis of individuals with disabilities in Asian countries. The current study examines levels of perceived stress and associated child and caregiver factors among caregivers of children with learning disabilities in the Malaysian context. An additional aim was to determine whether caregiver coping styles may be predictors of perceived stress. Methods: The Malay version of the Perceived Stress Scale with 10 items and the Brief COPE Scale were administered to a sample of 190 Malay caregivers of children with learning disabilities registered with community-based rehabilitation centres in Kelantan, a state in Peninsular Malaysia. Multiple linear regression analysis was applied to determine the predictors of perceived stress. Results: The mean total perceived stress score of caregivers was 16.96 (SD = 4.66). The most frequently used coping styles found among caregivers included religion, acceptance and positive reframing, while substance use and behavioural disengagement were least frequently used. Higher perceived stress was significantly predicted among caregivers with fewer children, frequent use of instrumental support and behavioural disengagement coping, and lack of emotional support and religious coping. Conclusion: Findings indicate that the perceived stress levels among caregivers were significantly predicted by different coping styles. It is vital to help the caregivers improve their good coping styles in order to reduce their stress levels.
\end{abstract}

Keywords: stress, coping styles, parents, caregivers, children, disabilities

\section{Introduction}

Many terms and definitions are used globally to describe children or adults with learning disabilities. In the United States (USA), there are three influential definitions of learning disability: Individual with Disabilities Education Act (IDEA) 1997; National Joint Committee on Learning Disabilities (NJCLD) 1997; and the definition of the Interagency Committee on Learning Disabilities (CLD) 1988 (1). Lerner (1) concluded from a review of the three definitions 
that they have several common elements: (i) central nervous system dysfunction; (ii) uneven growth pattern and psychological processing deficits; (iii) difficulty in academic and learning tasks; (iv) discrepancy between achievement and potential; and (v) the exclusion of other causes such as mental retardation, emotional disturbance, hearing and visual impairment, or the environment. The definition of learning disability used in the USA has been widely adopted by other countries, including Canada, Australia, Japan, Hong Kong, and South Korea (2). This definition refers to the term 'specific learning disabilities' such as dyslexia, dyscalculia, dysgraphia, and other conditions in the current international context (2). In the United Kingdom (UK), the term general learning disability has now been recommended to replace the term of mental retardation or mental handicap. A learning disability is usually described as significant impairment of intellectual, adaptive and social functioning before adulthood. The term 'learning disability/ difficulty' in the UK also includes those who have specific learning disabilities, but who do not have a significant impairment in intelligence (3).

In Malaysia, the description of 'learning disabilities' used may be likened to the definition used in the UK which refers to individuals with intellectual, social, and adaptive impairment due to various causes (2-3). The Department of Social Welfare under the Ministry of Women, Family, and Community Development Malaysia has defined 'learning disabilities' as disorders in learning, cognition and intelligence that is inconsistent with the chronological age. Conditions included under this category are global developmental delay (less than 5 years old), Down syndrome, autism spectrum disorders (ASD), attention deficit hyperactive disorder (ADHD), intellectual disability (more than 5 years old), and specific learning disabilities (e.g. dyslexia, dyscalculia and dysgraphia) (4). A child with a learning disability shows an uneven pattern of cognitive and social development. He or she finds it more difficult to learn, understand, communicate, play, and do other things compared with other children of the same age (3).

Raising a child with learning disability is often stressful, as the parents have to face with many changing demands related to the specific needs of their child. Previous works showed that the parenting stress level is higher in parents of children with learning disabilities than in parents of normal children $(5-8)$. The stress level experienced by caregivers of children with learning disability depends on multiple factors including parental coping styles. Coping is defined as the effort one make to manage or respond to harmful or stressful situations, including stressors related to caregiving a child with disability (9). It seems that successful adaptation to child's disability depends on how parents cope with the stress.

Some parents may have particular preferred coping strategies in their responses to different stressful situations. The literature has shown that caregivers use a broad range of coping strategies. There are indications that some strategies are more successful in some situations than in others $(5,10)$. A local study reported that decreased parenting stress levels were correlated with the use of acceptance, religious and optimist coping styles, whereas the most significant predictor of parenting stress was lack of acceptance of having a child with Down syndrome (10). In a crosscultural study, poorer maternal mental health among mothers of children with intellectual disability was related with greater use of emotional focused coping, but no relationship was found between coping strategies used and child-related stress (11). Differences in parental coping styles were also noted between those with children with learning disabilities and children without disabilities. Dabrowska and Pisula (5) found that parental stress in the parents of children with autism and Down syndrome was predicted by emotion-oriented coping, whereas task-oriented coping predicted parental stress in the parents of typically developing children.

Psychological stress reactions following a diagnosis of childhood learning disability involve the risk of long-term psychosocial impact for the parents and families. Parental stress is a strong predictor and can be a mediator of caregivers' psychological well-being, and usually turn to results in decisions to place the children with intellectual disabilities in the care of others (12). Therefore, it is very important to recognise caregivers who experience stress and their types of coping styles in order to provide improved informational resources and support services that meet the needs of caregivers. In addition, a majority of both international and local research has focused on stress and coping mechanisms among parents of children with specific age and diagnosis. Research that includes caregivers of more comprehensive age groups and diagnoses of individuals with learning disabilities in Malaysia is warranted. 
Original Article | Perceived stress and coping styles caregivers

The aims of this study were to determine the level of perceived stress and the most common coping styles used by the caregivers of children with learning disabilities in Malaysia setting. We also determined associations between perceived stress and socio-demographics and child's disability related factors. A further objective was to answer the question of whether coping styles are predictors of caregivers' perceived stress.

\section{Materials and Methods}

\section{Study design and participants}

This cross-sectional study was conducted in community-based rehabilitation (CBR) centres for disabled people under the authority of the Department of Social Welfare in Kelantan, the most north-eastern state of Peninsular Malaysia. The participants were parents or guardians (herein "caregivers") of children with learning disabilities who registered to the CBR and met the inclusion criteria as follows: (i) those who are primary caregivers; (ii) who have a child with the diagnosis of Down syndrome, ASD, ADHD, global developmental delays, intellectual disability, or specific learning disabilities; (iii) aged of 18 years old and below, and who (iv) lives at home. Caregivers who were absent during the study period and/or demonstrated a severe mental illness were excluded from the study.

Sample size was calculated for multiple linear regression test using G-Power version 3.1.9.2 software (13). With significant level $(\alpha)$ of $5 \%$ two-tailed, power of $80 \%$, effect size of 1.5 and number of predictors of 30 , the total sample size calculated was 206 after considering $10 \%$ of non-response rate. However, only 190 returned the completed survey questionnaire and were included in the analysis. One-stage cluster random sampling was applied in this study. In simple one-stage cluster sampling, simple random sampling is used to select the primary sampling units or clusters. All units in the sampled clusters are selected for the study. In order to obtain the required sample size, $22 \mathrm{CBR}$ centres (clusters) were randomly drawn from three regions (northern, centre, and southern) in the state of Kelantan. All eligible caregivers in the selected CBR centres were then recruited into the study.

\section{Procedures}

Between February and May 2015, caregivers were invited to participate in the study at their respective CBR. A guided self-administered questionnaire was distributed to the eligible caregivers. Researchers explained the study rationale and obtained written informed consent prior to the caregivers answering the questionnaire. Structured interviewing was applied if participants were illiterate. This study was approved by the Universiti Kebangsaan Malaysia Research Ethics Committee and the Department of Social Welfare.

\section{Instruments}

A set of self-administered and guided questionnaire in Malay version with three sections was used as research instrument. Three measures were included: a Background Information Section; the Perceived Stress Scale 10 items (PSS-10); and the Brief COPE Scale.

\section{Background information sheet}

Background information consisted of sociodemographic characteristics of the caregivers and their children, and disability related information of the child. Socio-demographic characteristics included age, relationship to the child, gender, race, marital status, occupation, educational level, number of children and disabled children, monthly household income, financial support received for the child and family per month, and chronic illness in the caregivers. Disability-related variables included time since diagnosis (duration of disability), reported medical or health problems, types of diagnosis, and care dependency. Reported medical or health problems were measured by asking the caregivers whether their child had other medical or health problems such as epilepsy, heart problems, and asthma. Care dependency was defined as the number of life domains on which their child needs care (eight items-physical, mobility, eating and drinking, medication use, coping with devices/ tools, entertaining, contact with other children, education). This scale ranges from o to 8, where $\mathrm{o}$ indicates that the child does not need support at all, and score 8 indicates that the child needs full support (14). The pilot study showed that this scale had good internal consistency reliability with Cronbach's alpha $=0.86$.

\section{Perceived Stress Scale 10 items (PSS-10)}

The PSS-10 as developed by Cohen et al. (15) was used for measuring the perception of stress. The questions in the PSS-10 ask about feelings and thoughts during the last month. The 10 items of PSS-10 were rated on five- 
point Likert scale based on the frequency of the stressful event experienced by the participant ( $\mathrm{o}=$ never, $1=$ almost never, 2 = sometimes, 3 = fairly often, 4 = very often). Individual scores on the PSS-10 range from o to 40, with higher scores indicating higher perceived stress. The Malay version of PSS-10 had good internal consistency reliability with Cronbach's alpha coefficient 0.78 for the overall scale. It also had good factor loading values for all items (0.67 to o.84) (16).

\section{Brief COPE Scale}

The Brief COPE inventory (17) was used to measure coping styles of the caregivers. It consists of 28 items on various aspects of coping mechanism. The coping styles are classified into 14 subscales: self-distraction, active coping, denial, substance use, use of emotional support, use of instrumental support, behavioural disengagement, venting, positive reframing, planning, humour, acceptance, religion, and self-blame. Self-distraction refers to focusing on alternative activities to take one's mind off the problems. Active coping is the process of taking active steps to try to eliminate the stressor or to reorganise its effects. Denial is defined as the refusal to believe that a stressor exists, or of trying to act as though the stressor is not real. The opposite of denial is acceptance, which is a functional coping reaction in which an individual acknowledges the reality of a stressful situation in an effort to deal with the situation (17-18).

Use of emotional support is a type of emotion-focused coping which consists of receiving moral support, sympathy, or understanding from others. Instrumental support is an aspect of problem-focused coping which involves seeking advice, help or information (18). Behavioural disengagement is helplessness or giving up the attempt to attain goals to solve the problems. Venting is the tendency to focus on whatever distress or upset individual is experiencing and to ventilate those feelings. Positive reframing is a type of emotionfocused coping which construing a stressful transaction in positive terms, and may lead a person to resume active and problem-focused coping actions. Another dimension, planning, consists of thinking about how to handle a stressor which engages with action strategies, thinking about what steps to obtain and how best to cope with the problem. Religion is an active coping tactic in which the individual tends to turn to religion in times of stress. Humour coping is making jokes or fun of the stressful situation. Self-blame means criticising oneself for responsibility in the situation. Substance use coping means taking alcohol or other drugs to deal with the stressors (17-18).

Each item in the Brief COPE is measured using 4-point Likert scale, with 1 = "I haven't been doing this at all", 2 = "I've been doing this a little bit", 3 = "I've been doing this a medium amount", and 4 = "I've been doing this a lot". A previous study on the validity and reliability of the Malay version of Brief COPE Scale has confirmed that it has fairly good reliability and validity. The internal consistency reliability indicated by the Cronbach's alpha values ranged from 0.51 to 0.99 (19).

\section{Statistical analysis}

Data analysis was conducted using IBM SPSS 22.0 (IBM Corp., USA). Descriptive analysis was used to describe socio-demographic information, disability related variables, perceived stress and coping styles. Results were presented as mean and standard deviation (SD) for normally distributed data. Median and interquartile range (IQR) were used to describe skewed data. For categorical data, results were presented as frequency and percentage (\%). Independent $t$-test was used to compare mean perceived stress score of the variables with two groups such as gender. One-way ANOVA was applied to test significant mean differences for the variables with more than two groups such as marital status. Pearson's correlation or Spearman's correlation analysis was used to describe associations between total perceived stress score and numerical independent variables (e.g. age, care dependency). Finally, multiple linear regression analysis was performed to determine the predictors of perceived stress. The clinically relevant variables with $P$-values of less than 0.25 from the univariable analyses were included into variable selection method in the multiple linear regression analysis. The significance level was set at 0.05 significance (two-tailed). Interactions, multicollinearity, and model assumptions were checked.

\section{Results}

Profiles of caregivers and children with learning disabilities

The mean age of 190 caregivers of children with learning disabilities in this study was 44.67 
Original Article | Perceived stress and coping styles caregivers

$(\mathrm{SD}=9.73)$ years, and ranged from 18 to 69 years. All participants were Malays. The majority of the participants were the children's biological parents (93.2\%), married (88.9\%), otherwise unemployed (62.6\%), and had secondary school education (71.6\%). The educational level of 43 caregivers (22.6\%) was low (having no formal or only primary school education) and few of them had tertiary education (5.8\%). Their median monthly household income was Malaysia Ringgit $(\mathrm{MYR}) 800(\mathrm{IQR}=\mathrm{MYR} 700)$, with minimum and maximum incomes of MYR 100 and MYR 800o, respectively (USD $1=$ MYR 4.19). The median financial support received per month from the Department of Social Welfare or other organisations was MYR 150 (IQR = MYR o). The majority of them indicated that they had five or fewer children (58.4\%) and one disabled child (88.9\%). Fifty-three (27.9\%) of the caregivers had a chronic illness such as diabetes mellitus, hypertension or heart diseases. The sociodemographic data of caregivers in the study are presented in Table 1.

The children with learning disabilities had a mean age of 10.49 (SD $=4.80)$ years. A majority were boys $(56.3 \%)$. Seventy-nine $(41.6 \%)$ were reported to have other medical problems or comorbidities such as heart problems, epilepsy, asthma, or other impairments. In terms of diagnosis, the majority of them were children with Down syndrome (52.6\%). Only two children with ADHD (1.1\%). The mean time since diagnosis was 9.03 ( $\mathrm{SD}=5.03$ ) years, and the mean care dependency was $30.53(\mathrm{SD}=15.82)$. Table 2 shows demographic and disability related variables of the children.

\section{Perceived stress and coping styles of the caregivers}

Table 3 presents descriptive statistics of perceived stress and coping styles of the caregivers. The mean total PSS-10 score of all 190 caregivers was $16.96(\mathrm{SD}=4.66)$, with a minimum score of 4.00 and maximum score of 30.00. According to PSS-10 scoring by Kelly and Percival (20), the mean total perceived stress score of these caregivers was considered as slightly higher than average and health concern level was high (total scores ranging from 16 to 20). Meanwhile, the perceived stress levels of individuals with a total score of 21 or over were much higher than average and their health concern levels were also very high (20).

The most frequently used coping styles were religion (mean $=7.02, \mathrm{SD}=1.37)$, acceptance (mean $=6.19, \mathrm{SD}=1.68)$ and positive reframing
$($ mean $=5 \cdot 71, \mathrm{SD}=1.71)$. Substance use $($ mean $=$ 2.07, $\mathrm{SD}=0.49$ ) and behavioural disengagement (mean $=2.96, \mathrm{SD}=1.33$ ) were less frequently used by these caregivers.

\section{Associations between perceived stress and socio-} demographics and disability related variables

Univariable analysis showed that perceived stress was associated with number of children in the family. Pearson's correlation analysis showed that perceived stress had significant negative and poor correlation with number of children $(r=-0.219, P$-value $=0.002)$. Perceived stress score also had poor and non-significant correlation with care dependency, time since diagnosis, age, number of disabled children, income, and financial support received. Other disability-related variables (child's diagnosis and reported medical/health problems) and socio-demographic variables (gender of child and caregiver, caregiver's occupation, education, marital status and chronic illness) also did not show any significant results. Tables 4 and 5 show the results of the Independent $t$-test and oneway ANOVA respectively. Results of correlation analysis are presented in Table 6.

\section{Predictors of perceived stress}

For multiple linear regression analysis, caregiver's socio-demographic and coping styles variables with $P$-value $<0.25$ were introduced into the model. Backward variable selection method was used to select the predictors of perceived stress. The analysis revealed that number of children and use of emotional support, use of instrumental support, behavioural disengagement and religion coping styles were the significant predictors of perceived stress. Table 7 presents the results of the final model of regression analysis.

The final regression model showed that perceived stress was best predicted by the use of instrumental support coping $(\beta=0.40, P$-value < o.001). The results also indicated that caregivers with higher use of instrumental support and behavioural disengagement coping styles had higher perceived stress. Caregivers with more children and those using higher emotional support and religion coping demonstrated a lower level of perceived stress. Approximately $28 \%$ of variations in total perceived stress score were explained by these variables $\left(R^{2}=0.281\right)$. 
Table 1. Distribution of socio-demographic of the caregivers $(n=190)$

\begin{tabular}{|c|c|c|}
\hline Characteristics & Mean (SD) & Frequency (\%) \\
\hline Age (years) & $44.67(9.73)$ & \\
\hline $\begin{array}{l}\text { Number of children } \\
\quad 1-5 \\
6-10 \\
11-15\end{array}$ & & $\begin{array}{l}111(58.4) \\
70(36.8) \\
9(4.7)\end{array}$ \\
\hline $\begin{array}{l}\text { Number of disabled children } \\
\text { One } \\
\text { Two and more }\end{array}$ & & $\begin{array}{r}169(88.9) \\
21(11.1)\end{array}$ \\
\hline $\begin{array}{l}\text { Relationship to the children } \\
\text { Father/Mother } \\
\text { Grandfather/Grandmother } \\
\text { Siblings } \\
\text { Others }\end{array}$ & & $\begin{array}{cc}177 & (93.2) \\
4 & (2.1) \\
6 & (3.1) \\
3 & (1.6)\end{array}$ \\
\hline $\begin{array}{l}\text { Gender } \\
\text { Male } \\
\text { Female }\end{array}$ & & $\begin{array}{l}39(20.5) \\
151(79.5)\end{array}$ \\
\hline $\begin{array}{l}\text { Marital status } \\
\text { Married } \\
\text { Not married }\end{array}$ & & $\begin{array}{l}169(88.9) \\
21(11.1)\end{array}$ \\
\hline $\begin{array}{l}\text { Occupation } \\
\text { Unemployed } \\
\text { Private employee } \\
\text { Government employee } \\
\text { Self-employed }\end{array}$ & & $\begin{array}{c}119(62.6) \\
8(4.2) \\
13(6.8) \\
50(26.3)\end{array}$ \\
\hline $\begin{array}{l}\text { Educational level } \\
\text { No formal education } \\
\text { Primary school } \\
\text { Secondary school } \\
\text { University/college }\end{array}$ & & $\begin{array}{c}8(4.2) \\
35(18.4) \\
136(71.6) \\
11(5.8)\end{array}$ \\
\hline $\begin{array}{l}\text { Monthly household income (MYR) } \\
\text { Monthly financial support received (MYR) } \\
\text { Chronic diseases }\end{array}$ & $\begin{array}{c}800.00(150.00)^{\mathrm{a}} \\
700.00(0.00)^{\mathrm{a}}\end{array}$ & \\
\hline $\begin{array}{l}\text { Yes } \\
\text { No }\end{array}$ & & $\begin{array}{l}53(27.9) \\
137(72.1)\end{array}$ \\
\hline
\end{tabular}

${ }^{a}$ Median (IQR) 
Original Article | Perceived stress and coping styles caregivers

Table 2. Characteristics of children with learning disabilities $(n=190)$

\begin{tabular}{lcc}
\multicolumn{1}{c}{ Characteristics } & Mean (SD) & Frequency (\%) \\
Age (years) & $10.49(4.80)$ & \\
Gender & & $107(56.3)$ \\
Boy & & $83(43.7)$ \\
Girl & & $79(41.6)$ \\
Reported medical/health problems & & $111(58.4)$ \\
Yes & & \\
No & $9.03(5.03)$ & \\
Time since diagnosis (duration of disability) (years) & $30.53(15.82)$ & $100(52.6)$ \\
Care dependency score & & $2(1.1)$ \\
Types of diagnosis: & & $22(11.6)$ \\
Down syndrome & & $16(8.4)$ \\
ADHD & & $41(21.6)$ \\
Autism & & $9(4.7)$ \\
Global developmental delay & & \\
Intellectual disability & & \\
Specific learning disability & & \\
\hline
\end{tabular}

${ }^{a}$ Scale 0-8 (high score representing high dependency); maximum score: 64

Table 3. Mean score of perceived stress and coping styles among caregivers $(n=190)$

\begin{tabular}{lc}
\multicolumn{1}{c}{ Scale } & Mean (SD) \\
Perceived Stress & $16.96(4.66)$ \\
Total score & \\
Coping Styles & $4.85(1.60)$ \\
Self-distraction & $5.51(1.56)$ \\
Active coping & $3.41(1.52)$ \\
Denial & $2.07(0.49)$ \\
Substance use & $4.83(1.61)$ \\
Use of emotional support & $4.66(1.77)$ \\
Use of instrumental support & $2.96(1.33)$ \\
Behavioural disengagement & $4.13(1.53)$ \\
Venting & $5.71(1.71)$ \\
Positive reframing & $5.64(1.39)$ \\
Planning & $4.34(1.35)$ \\
Humour & $6.19(1.68)$ \\
Acceptance & $7.02(1.37)$ \\
Religion & $3.42(1.53)$ \\
Self-blame & \\
\hline
\end{tabular}


Table 4. Comparison of mean perceived stress score between child's and caregiver's characteristics using Independent $t$-test

\begin{tabular}{|c|c|c|c|c|c|}
\hline Variable & $n$ & Mean (SD) & $\begin{array}{c}\text { Mean Difference } \\
(95 \% \mathrm{CI})\end{array}$ & $t(d f)$ & $P$-value \\
\hline \multicolumn{6}{|l|}{ Child characteristics } \\
\hline $\begin{array}{l}\text { Gender } \\
\text { Boy } \\
\text { Girl }\end{array}$ & $\begin{array}{r}107 \\
83\end{array}$ & $\begin{array}{l}17.12(4.94) \\
16.75(4.29)\end{array}$ & $\begin{array}{c}0.37 \\
(-0.97,1.72)\end{array}$ & $0.548(188)$ & 0.584 \\
\hline $\begin{array}{l}\text { Reported medical/ } \\
\text { health problems } \\
\text { No } \\
\text { Yes }\end{array}$ & $\begin{array}{l}111 \\
79\end{array}$ & $\begin{array}{c}16.83(4.50) \\
17.14(4.91)\end{array}$ & $\begin{array}{c}-0.31 \\
(-1.67,1.05)\end{array}$ & $-0.451(188)$ & 0.652 \\
\hline Caregiver characterist & & & & & \\
\hline $\begin{array}{l}\text { Gender } \\
\text { Male } \\
\text { Female }\end{array}$ & $\begin{array}{c}39 \\
151\end{array}$ & $\begin{array}{l}17.05(3.89) \\
16.93(4.85)\end{array}$ & $\begin{array}{c}0.12 \\
(-1.54,1.77)\end{array}$ & $0.140(188)$ & 0.889 \\
\hline $\begin{array}{l}\text { Marital status } \\
\text { Married } \\
\text { Not married }\end{array}$ & $\begin{array}{c}169 \\
21\end{array}$ & $\begin{array}{l}16.83(4.61) \\
18.00(5.04)\end{array}$ & $\begin{array}{c}-1.17 \\
(-3.30,0.96)\end{array}$ & $-1.086(188)$ & 0.279 \\
\hline $\begin{array}{l}\text { Chronic diseases } \\
\text { No } \\
\text { Yes }\end{array}$ & $\begin{array}{c}137 \\
53\end{array}$ & $\begin{array}{l}17.08(4.77) \\
16.64(4.42)\end{array}$ & $\begin{array}{c}0.44 \\
(-1.05,1.93)\end{array}$ & $0.581(188)$ & 0.562 \\
\hline
\end{tabular}

Table 5. Comparison of mean perceived stress score among child's and caregiver's characteristics using ANOVA

\begin{tabular}{|c|c|c|c|}
\hline Variable & Mean (SD) & $F(d f)$ & $P$-value \\
\hline $\begin{array}{l}\text { Types of diagnosis } \\
\text { Down syndrome } \\
\text { ADHD } \\
\text { Autism } \\
\text { Global developmental delay } \\
\text { Intellectual disability } \\
\text { Specific learning disability }\end{array}$ & $\begin{array}{l}16.41(4.76) \\
17.00(1.41) \\
18.00(0.95) \\
16.06(4.22) \\
17.98(4.81) \\
17.44(4.25)\end{array}$ & $1.025(5,184)$ & 0.404 \\
\hline Caregiver characteristics & & & \\
\hline $\begin{array}{l}\text { Occupation } \\
\text { Unemployed } \\
\text { Private employee } \\
\text { Government employee } \\
\text { Self-employed }\end{array}$ & $\begin{array}{l}16.55(4.81) \\
19.13(4.36) \\
17.85(2.27) \\
17.34(4.77)\end{array}$ & $1.144(3,186)$ & 0.332 \\
\hline $\begin{array}{l}\text { Educational level } \\
\text { No formal education } \\
\text { Primary school } \\
\text { Secondary school } \\
\text { University/college }\end{array}$ & $\begin{array}{l}16.25(6.90) \\
16.40(5.12) \\
17.04(4.51) \\
18.27(3.13)\end{array}$ & $0.529(3,186)$ & 0.663 \\
\hline
\end{tabular}


Original Article | Perceived stress and coping styles caregivers

Table 6. Correlation between perceived stress and child's and caregiver's characteristics

\begin{tabular}{lcc}
\multicolumn{1}{c}{ Variable } & $\begin{array}{c}\text { Pearson's correlation } \\
\text { coefficient }(\boldsymbol{r})\end{array}$ & P-value \\
Child characteristics & & 0.431 \\
Age & 0.057 & 0.456 \\
Time since diagnosis & -0.057 & 0.615 \\
Care dependency & $0.037^{\mathrm{a}}$ & \\
Caregiver characteristics & & 0.082 \\
Age & -0.126 & 0.320 \\
Number of disabled children & $0.073^{\mathrm{a}}$ & $0.002^{\mathrm{b}}$ \\
Number of children & -0.219 & 0.842 \\
Monthly household income & $0.015^{\mathrm{a}}$ & 0.255 \\
Financial support received & $-0.089^{\mathrm{a}}$ & \\
\hline
\end{tabular}

a Spearman's correlation coefficient $\left(r_{s}\right)$

${ }^{\mathrm{b}}$ Significant at 0.05 level (2-tailed)

Table 7. Predictors of perceived stress among caregivers

\begin{tabular}{lccc}
\multicolumn{1}{c}{ Variable } & $\boldsymbol{b}(\mathbf{9 5 \%} \mathbf{C I})^{\mathrm{a}}$ & $\boldsymbol{\beta}^{\mathrm{b}}$ & $\boldsymbol{P}$-value \\
Number of children & $-0.34(-0.56,-0.13)$ & -0.20 & 0.002 \\
Use of emotional support & $-0.63(-1.07,-0.19)$ & -0.22 & 0.005 \\
Use of instrumental support & $1.04(0.64,1.44)$ & 0.40 & $<0.001$ \\
Behavioural disengagement & $0.98(0.54,1.42)$ & 0.28 & $<0.001$ \\
Religion & $-0.72(-1.16,-0.28)$ & -0.21 & 0.002 \\
\hline
\end{tabular}

a Adjusted unstandardised regression coefficient

${ }^{\mathrm{b}}$ Standardised regression coefficient

Backward variable selection method applied. Model assumptions were fulfilled. There were no interactions and multicollinearity detected. Coefficient of determination $\left(R^{2}\right)=0.281$

\section{Discussion}

In this study, the mean total score of PSS-10 was 16.96, indicating a stress level was slightly higher than average, while the average score is between 12 and 15 (20). Our finding was consistent with previous studies that found parents of individuals with learning disabilities to be under considerable stress $\left(5^{-8}, 10\right)$. Higher stress levels in caregivers might increase susceptibility to stress-induced illness and affect the adjustment to taking care of their child with learning disability.

Additionally, this present study demonstrates that the caregivers used a mixture of coping strategies overall. They were more inclined to use religious, acceptance and positive reframing coping styles. This result supported the other local findings which shows that parents of children with Down syndrome and hearing impairment used religious, active coping, and acceptance as their coping styles (10, 21). It was also noted that our caregivers used positive coping strategies which can help them to adapt effectively in caring for a disabled child. A previous local study also found that the majority (57.4\%) of parents of children with disabilities were considered to have good coping strategies (22). Consistent with the current findings of less frequent use of substance use and behavioural disengagement by the caregivers, past study also found similar results in their samples (21). Behavioural disengagement and substance use were least frequently seen in our caregivers, perhaps due to strong religious beliefs and cultural norms. Unfortunately, the present 
study did not investigate factors contributing to different uses of coping styles.

With regard to caregivers' sociodemographic characteristics, our study showed that only number of children in the family was associated with caregivers' perceived stress. The next hypothesis concerned coping styles as predictors of perceived stress. Predictors were selected based on the basis of previous univariable analysis showing the significance of number of children variable in shaping stress profile. Other non-significant socio-demographic and disability related variables were not included in the regression analysis. The results of multiple linear regression analysis revealed that one socio-demographic variable (number of children) and four coping styles (use of instrumental support, use of emotional support, behavioural disengagement and religion) are predictors of the level of perceived stress in the studied samples.

The current study found an interesting significant finding that is negative relationship was observed between number of children in the family and perceived stress score. In contrast to previous studies that found positive relationship between number of children and level of stress and anxiety (5, 23), our study demonstrated that the more number of children that a family has, the lesser the stress of caregiver. Despite the belief that a bigger family size has more of a negative impact on caregivers, another local study also suggested that the higher the number of children in the family, the better parent and family functioning (24). The current findings warrant further exploration in the context of our culture.

With regards to coping styles of caregivers, the use of instrumental support, use of emotional support, behavioural disengagement and religious coping styles were found to be significant predictors of total perceived stress. As expected, caregivers using emotional support and religion more frequently demonstrated a lower level of stress. Ha et al. (25) suggested the detrimental impact on mental health of parents is reduced when parents had more positive support from family members. Other studies also reported that more emotional support was related with better cognitive and social functioning (26) and health-related quality of life of the parents (14). When under stress, an individual might turn to religion for many reasons as religion serves as a source of emotional support, a vehicle for positive reinterpretation and growth, or a tactic of active coping with a stressor (18). Religion is recognised as major resource for caregivers in our population when dealing with a stressful event. Most Malays are Muslims who are taught to accept their disabled children as part of their fate (the concept of redha) and a way to make a person or family stronger and more faithful to God.

Interestingly, our results indicated the caregivers who were using more instrumental support and behavioural disengagement coping had higher level of stress. Findings showed that seeking instrumental support such as advice, assistance, or information, particularly from professionals, may lead to greater stress because of emerging problems. The results of previous study have indicated that insufficient support from services and difficulties associated with accessing funding can increase the stress felt by parents (27). Qualitative exploration discovered that not every parent found contact with professionals as helpful and they often must be extremely proactive and work hard to find the services they need $(11,27)$. Behavioural disengagement is a bad coping strategy that reduces an individual's effort to deal with stressor, even giving up the attempt to accomplish goals with which the stressor is interfering (18). Caregivers use behavioural disengagement when they felt helplessness and expect poor coping outcomes.

The present study has certain limitations which restrict its conclusions. Although the present study has included a considerable number of caregivers, the caregivers in this study were drawn from the list of children with learning disabilities registered with CBR centres and belonged to the Malay population and therefore limit generalisability. It is recommended that future work would benefit from access to a larger and more varied pool of participants to enhance external validity. In addition, the severity of children's disabilities, as well as behavioural problems which may affect parental stress, were not accounted for in the present study. Future research efforts may consider the child's factors and other potential family stressors such as caregiving demands, financial strain, and marital satisfaction. Despite its limitations, this study has revealed new information about factors influencing stress in persons caring children with learning disabilities in Malaysia. These results have practical implications. It is important for health professionals to understand the coping styles of these caregivers in order to help them to reduce their stress. Specifically, healthcare providers in 
Original Article | Perceived stress and coping styles caregivers

this country must endeavour to improve current psychoeducation programmes to better educate caregivers to develop effective coping skills and better manage their stress.

\section{Conclusion}

Caregivers of children with learning disabilities in this population had slightly higher levels of stress than average recommended by Kelly and Percival (20). The most frequently employed coping styles among caregivers in this study were religion, acceptance, and positive reframing. Higher perceived stress was significantly predicted by frequent use of instrumental support and behavioural disengagement coping styles. Caregivers with more children and those with frequent use of emotional support and religion coping were found to have lower perceived stress.

\section{Acknowledgement}

We wish to acknowledge the financial support from Fundamental Research Grant Scheme (FRGS) (Grant No.: FRGS/2/2014/SSo2/ $\mathrm{UKM} / \mathrm{O} 2 / 2$ ) of the Ministry of Higher Education Malaysia used to fund this study. We also gratefully acknowledged the Department of Social Welfare for their approval allowing us to conduct this study at the CBR centres in the state. Special thanks went to all caregivers and supervisors/teachers at CBR in Kelantan for their cooperation in this study.

\section{Funds}

Fundamental Research Grant Scheme (FRGS) (Grant No.: FRGS/2/2014/SSo2/UKM/02/2).

\section{Authors' Contributions}

Conception and design: SNII, II Analysis and interpretation of the data: SNII Drafting of the article: SNII

Critical revision of the article for important intellectual content: II, AAR, NZMS, NCD, SHL Final approval of the article: AAR, NCD, SHL Statistical expertise: II, NZMS, SHL

Obtaining of funding: SNII, II,

Administrative, technical, or logistic support: MFMI

Collection and assembly of data: SNII, MFMI

\section{Correspondence}

Dr Ismarulyusda Ishak BSc (Biomedical Science) (UKM), PhD (Community Health) (UKM)

School of Diagnostic and Applied Health Sciences,

Faculty of Health Sciences,

Universiti Kebangsaan Malaysia,

Jalan Raja Muda Abdul Aziz,

50300 Kuala Lumpur, Malaysia.

Tel: +6019 2250528

Fax: +60326929032

E-mail: ismarul@ukm.edu.my

\section{References}

1. Lerner JW. Learning disabilities: theories, diagnosis, and teaching strategies. Boston: Houghton Mifflin Company; 2003.

2. Dzalani H, Shamsuddin K. A review of definitions and identifications of specific learning disabilities in Malaysia and challenges in provision of services. Pertanika J Soc Sci Hum. 2014;22(1):118.

3. Holland K. Factsheet: Learning disabilities. Birmingham: British Institute of Learning Disabilities; 2011.

4. Malaysian Department of Social Welfare. Pendaftaran orang kurang upaya [Internet]. Putrajaya: Jabatan Kebajikan Masyarakat Malaysia; 2013 [cited 2014 Nov 1]. Available from: https://www.jkm.gov.my/content.php? pagename $=$ pendaftaran_orang_kurang_upaya \&lang $=\mathrm{bm}$

5. Dabrowska A, Pisula E. Parenting stress and coping styles in mothers and fathers of preschool children with autism and Down syndrome. $J$ Intellect Disabil Res. 2010;54(3):266-280. https://dx.doi.org/10.1111/j.1365-2788.2010. 01258.x

6. Gallagher S, Phillips AC, Carroll D. Parental stress is associated with poor sleep quality in parents caring for children with developmental disabilities. J Pediatr Psychol. 2010;35(7):728737. https://dx.doi.org/10.1093/jpepsy/jspo93 
7. Hoffman CD, Sweeney DP, Hodge D, LopezWagner MC, Looney L. Parenting stress and closeness: mothers of typically developing children and mothers of children with autism. Focus Autism Other Dev Disabl. 2009;24(3):178-187. https://dx.doi.org/10.1177/ 1088357609338715

8. Merkaj V, Kika M, Simaku A. Symptoms of stress, depression and anxiety between parents of autistic children and parents of tipically developing children. Academic Journal of Interdisciplinary Studies. 2013;2(2):345-352. https://dx.doi.org/10.5901/ajis.2013.v2n2p345

9. Nor Zaidah AH, Khairani O, Normah CD. Coping styles of mothers with disabled children at rural community rehabilitation centres in Muar, Malaysia. Med J Malaysia. 2004;59(3):384-390.

10. Norizan A, Shamsuddin K. Predictors of parenting stress among Malaysian mothers of children with Down syndrome. J Intellect Disabil Res. 2010;54(11):992-1003. https://dx.doi. org/10.1111/j.1365-2788.2010.01324.x

11. McConkey R, Truesdale-Kennedy M, Chang MY, Jarrah S, Shukri R. The impact on mothers of bringing up a child with intellectual disabilities: A cross-cultural study. Int $J$ Nurs Stud. 2008;45:65-74. https://dx.doi.org/10.1016/j. ijnurstu.2006.08.007

12. Cramm JM, Nieboer AP. Psychological wellbeing of caregivers of children with intellectual disabilities: Using parental stress as a mediating factor. J Intellect Disabil. 2011;15(2):101-113. https://dx.doi.org/10.1177/1744629511410922

13. Faul F, Erdfelder E, Buchner A, Lang A-G. Statistical power analyses using $G^{*}$ Power 3.1: Tests for correlation and regression analyses. Behav Res Methods. 2009;41(4):11491160. https://dx.doi.org/10.3758/BRM.41.4.1149

14. Hatzmann J, Maurice-Stam H, Heymans HAS, Grootenhuis MA. A predictive model of healthrelated quality of life of parents of chronically ill children: the importance of care-dependency of their child and their support system. Health Qual Life Outcomes. 2009;7:72. https://dx.doi. org/10.1186/1477-7525-7-72

15. Cohen S, Kamarck T, Mermelstein R. A global measure of perceived stress. $J$ Health Soc Behav. 1983;24(4):385-396. https://dx.doi. org/10.2307/2136404
16. Al-Dubai SAR, Alshagga MA, Rampal KG, Sulaiman NA. Factor structure and reliability of the Malay version of the Perceived Stress Scale among Malaysian medical students. Malays $J$ Med Sci. 2012;19(3):43-49.

17. Carver CS. You want to measure coping but your protocol's too long. Consider the Brief COPE. Int $J$ Behav Med. 1997;4(1):92-100. https://dx.doi. org/10.1207/s15327558ijbmo401_6

18. Carver CS, Scheier MF, Weintraub JK. Assessing coping strategies: a theoretically based approach. $J$ Pers Soc Psychol. 1989;56(2):267-283. https://dx.doi.org/10.1037/o022-3514.56.2.267

19. Yusoff N, Low WY, Yip CH. Reliability and validity of the Malay version of Brief COPE Scale: a study on Malaysian women treated with adjuvant chemotherapy for breast cancer. Malays $J$ Psychiatry. 2009;18(1):1-9.

20. Kelly G, Percival M. Perceived stress scale [Internet]. [Place of publication unknown]: Health Science Investigation. 2006-2010 [cited 2015 May 1]. Available from: https:// healthsceneinvestigation.com/files/2010/07/ Percived-Stress-Scale.pdf.

21. Md Daud MK, Noor SSM, Yusoff MNCM, Abd Rahman N, Zakaria MN. Gender differences in coping skills of parents with hearing-impaired children. B-ENT. 2013;9:319-323.

22. Zubair IU. Coping mechanisms and quality of life of parents living with disabled children in Kelantan [minor research project report for Master of Public Health]. Kelantan: Universiti Sains Malaysia; 2014.

23. Bumin G, Gunal A, Tukel S. Anxiety, depression and quality of life in mothers of disabled children. S.D.Ü.Týp Fak. Derg. 2008;15(1):6-11.

24. Shukor SA. The impact of chronic illness among children on the family [minor research project report for Master of Public Health]. Kelantan: Universiti Sains Malaysia; 2011.

25. Ha JH, Greenberg JS, Seltzer MM. Parenting a child with a disability: The role of social support for African American parents. Families in Society: FAM SOC. 2011;92(4):405-411. https://dx.doi. org/10.1606/1044-3894.4150 
Original Article | Perceived stress and coping styles caregivers

26. Marchal JP, Maurice-Stam H, Hatzmann J, Trotsenburg ASPV, Grootenhuis MA. Health related quality of life in parents of six to eight year old children with Down syndrome. Res Dev Disabil. 2013;34:4239-4247. https://dx.doi. org/10.1016/j.ridd.2013.09.011
27. Davis E, Shelly A, Waters E, Boyd R, Cook K, Davern M. The impact of caring for a child with cerebral palsy: quality of life for mothers and fathers. Child Care Health Dev. 2009;36(1):6373. https://dx.doi.org/10.1111/j.1365-2214.2009. 00989.x 